ESTUDOS RB:P

\title{
Equidade e desempenho escolar: é possível alcançar uma educação de qualidade para todos?
}

Maria Alice Setúbal

\section{Resumo}

Nos últimos anos, verifica-se no Brasil a ampliação dos setores da sociedade que participam dos debates sobre educação. Uma das vozes que ganha cada vez mais força é a dos economistas que, de algum modo, estão orientados pelas teorias do capital humano. Este artigo procura debater algumas posições-chave assumidas por esse grupo de economistas, em particular as que foram apresentadas no livro Educação básica no Brasil: construindo o país do futuro. Esse debate é proposto a partir de três temas: os mecanismos institucionais de gestão, o lugar da escola e da família e, ainda, a educação no contexto da vulnerabilidade social. Por fim, o artigo procura apontar algumas premissas para que nosso sistema educacional possa ter ganhos de qualidade com equidade, sobretudo nos territórios urbanos em situação de alta vulnerabilidade social.

Palavras-chave: educação; políticas públicas; qualidade e equidade; capital humano. 


\section{Abstract \\ Equity and school performance: it is possible to achieve good quality education for all}

Recent years have witnessed the enlargement of Brazilian society groups that participate in educational debate. One of the voices that have gained increasing strength was that of the economists, somehow led by theories of human capital. This article discusses a few key positions taken by this group of economists; particularly those presented in the book Educação básica no Brasil: construindo o país do futuro. The debate is structured according to three themes: the institutional mechanisms of management, the role of school and family, and education in a socially vulnerable context. Finally, the article tries to point out some requirements that have to be met if our educational system is to make improvements in quality with equity, particularly in highly socially vulnerable urban areas.

Keywords: education; public policies; quality and equity; human capital.

A ampliação do debate da educação para diferentes setores da sociedade trouxe à tona interpretações e contribuições diversas que têm o mérito de envolver a sociedade na discussão de quais seriam os caminhos para se alcançar uma educação de qualidade para todos.

Dentre essas análises, a teoria do capital humano foi amplamente difundida no Brasil pelos economistas desde a década de 1970. A partir dos anos 90, passou a ser entendida, do ponto de vista das pessoas, como as capacidades e as competências que cada um deve adquirir no âmbito da escola para atingir uma posição melhor no mercado de trabalho. Nessa perspectiva, a educação enfatizou o capital humano individual que habilita as pessoas para a competição por trabalho. Do ponto de vista do mercado, o capital humano é visto como as capacidades humanas que são necessárias para que a atividade econômica possa se expandir e se diversificar num cenário de acirramento da concorrência internacional.

Vários estudos recentes buscam analisar um panorama da história da educação brasileira e latino-americana, dentre eles, os de Simon Schwartzman e Cristian Cox (2009), que organizaram um livro sobre as políticas educacionais com o objetivo de aproximar as visões de economistas, sociólogos e educadores. Os autores afirmam que as novas políticas educacionais deveriam centrar-se na agenda de transformações das capacidades das quais dependem os desempenhos dos docentes em 
sala de aula e os dos gestores nos centros de decisão, assim como os resultados de aprendizagem de alunos e sistemas escolares.

De forma direta ou indireta, a discussão atual sobre os rumos da educação brasileira passa por um debate que envolve uma postura, se não exclusiva, marcadamente defendida por uma perspectiva economicista, e é nesse âmbito que será concentrada esta análise. São inúmeros os trabalhos sobre educação publicados por economistas, e, obviamente, não existe uma uniformidade entre eles. O que há em comum é uma abordagem específica para analisar os problemas e os caminhos a serem propostos na área educacional.

Neste estudo, o debate será focado na obra Educação básica no Brasil, organizada por Fernando Veloso, Samuel Pessoa, Ricardo Henriques e Fábio Giambiagi em 2009 e prefaciada por Marcos Lisboa. Com a exceção de José Francisco Soares, estatístico da Universidade Federal de Minas Gerais (UFMG), os demais autores são economistas formados em universidades de primeira linha do Rio de Janeiro ou de São Paulo e vários têm pós-graduação fora do Brasil, especialmente nos Estados Unidos.

A visão da educação do ponto de vista dos economistas não é nova no Brasil, e remete-se aqui à ótima análise realizada por Almeida (2008) em "O assalto à educação pelos economistas". Nesse texto, a autora analisa o fortalecimento da posição dos economistas no campo educacional e o enfraquecimento da posição daqueles que ela chama de bacharéis-educadores. Ao retomar o debate da década de 1970 entre os economistas Carlos Langoni (1973) e Albert Fishlow (1972), ela mostra como as discussões dos economistas se deslocaram do binômio educação e crescimento econômico para o tema educação e distribuição de renda.

De forma resumida, para Fishlow, a renda do trabalho diminuiu nos anos 60 como consequência: 1) da compressão dos salários pelo controle do aumento salarial explicitado pelo Plano de Ação Econômica Governamental (Paeg), lançado em 1964; e 2) do impedimento legal de sindicatos e grevistas questionarem juridicamente reajustes salariais em face da inflação e do aumento da produtividade do trabalho. Em 1972, Langoni rebateu essa tese ao defender que a concentração de renda era resultado de um duplo movimento de efeito temporário: 1) aceleração do crescimento econômico em um país de renda per capita baixa; e 2) transformação da estrutura agrária em uma estrutura industrial, o que trouxe como consequência uma migração dos recursos para os espaços mais produtivos. Esse seria um efeito temporário de desequilíbrio do mercado de trabalho que levaria a um mecanismo autocorretor quando a oferta de trabalho mais qualificada se tornasse maior.

Nesse quadro, para Fishlow, o sistema educacional brasileiro era, em si mesmo, um mecanismo que mantinha a estrutura existente, reservando acesso ao diploma àqueles que tinham pais escolarizados e que dispunham de uma renda razoável. Nas réplicas e tréplicas, fica claro que na visão de Langoni a educação e a saúde eram mais consequências do desenvolvimento econômico do que suas molas propulsoras. Na retomada da educação nos anos 90, contexto da formação e das pesquisas realizadas pelos autores do livro Educação básica no Brasil, alguns debates feitos 
pelos economistas aproximam-se da concepção de Fishlow na relação entre renda e educação. A posição de Langoni, de que as desigualdades de renda são produzidas pelas desigualdades educacionais, também ecoa nos debates contemporâneos, como veremos adiante com a análise dos artigos.

Se as análises da educação brasileira realizadas por economistas datam de algumas décadas, pode-se, no entanto, considerar que foi nos últimos anos que esse tema ganhou o interesse de um número maior deles, gerando entre os educadores posições diferenciadas. Muitas vezes, como aponta Marcos Lisboa (2009), os estudos baseados em dados quantitativos têm sido desqualificados por puro preconceito, em nome de uma retórica que mais fala de um desejo do que seria a educação ideal do que em análises que confrontem a realidade como ela é. O autor vai além, observando que há vários anos os organizadores de Educação básica no Brasil se dedicam a trazer para o debate acadêmico brasileiro os resultados da pesquisa internacional sobre problemas sociais e desenvolvimento econômico.

Sem dúvida, tem grande mérito um trabalho que busca traçar um panorama da educação no Brasil nos últimos 15 anos, desde a educação infantil até o ensino médio, baseando-se em estudos e pesquisas acadêmicas. Tratando-se de economistas, é também interessante que esses estudos reflitam resultados eminentemente quantitativos, o que contribui para a compreensão dos gargalos educacionais, nem sempre percebidos pelos educadores que tendem a ter um olhar mais qualitativo. No entanto, como veremos adiante, não parece que a questão central esteja em termos de uma visão quantitativa versus uma visão qualitativa, ainda que essas diferenças se façam presentes.

O conjunto dos capítulos do livro Educação básica no Brasil expõe o panorama da educação brasileira, com seus avanços e fragilidades. Para efeito de análise, foram selecionados alguns capítulos considerados mais representativos para os aspectos discutidos neste artigo: Lisboa (2009), Veloso (2009a), Neri (2009), Barbosa Filho e Pessoa (2009), Soares e Marotta (2009), Ribeiro e Menezes Filho (2009), Veloso (2009b), Gremaud e Fernandes (2009), Ferraz (2009). Também é importante ressaltar que o objetivo não foi analisar cada um dos textos mencionados, mas sim introduzi-los no debate central.

O objetivo deste artigo é estabelecer um diálogo entre uma visão defendida por um grupo de economistas e outra mais ligada a educadores, buscando encontrar os pontos de interlocução possíveis entre essas posições. A tensão reside algumas vezes em uma oposição entre igualdade e mérito, outras entre integração e exclusão, ou ainda entre capital humano e socialização. Contudo, acredita-se que, a despeito das diferenças, a sociedade brasileira já construiu importantes consensos que são um legado a preservar. Não se trata, portanto, de averiguar quem tem razão, e sim de fazer uma reflexão sobre os resultados dos estudos presentes em Educação básica no Brasil à luz das experiências e dos trabalhos realizados por outros estudiosos da educação. 


\section{Mecanismos institucionais de gestão}

Como ponto de partida, é importante destacar que todos os estudos mencionados evidenciam direta ou indiretamente a tese comprovada teórica e empiricamente da relação positiva entre educação, crescimento econômico e diminuição das desigualdades sociais. No entanto, como se dá essa relação de forma mais aprimorada ainda é palco de discussões. O estudo de Barbosa Filho e Pessoa (2009) demonstra que cada ano de escolaridade formal eleva, na média, a renda do trabalhador em 10\% e a renda per capita em 7\%. Há que se entender melhor como esses indicadores foram construídos, pois os índices da educação devem ser analisados de acordo com os de crescimento econômico, em perspectiva histórica, ou seja, ainda que o nível educacional constitua um fator fundamental, tomado de forma isolada não tem impacto na renda de forma significativa, como mostra o caso de Cuba. Do mesmo modo, pode haver períodos de baixo crescimento ou mesmo de retração da economia em países com índices educacionais elevados, como foi o caso de vários Estados europeus nos últimos anos.

As controvérsias são inúmeras. Eric Hanushek (2008), economista que defende a relação positiva entre educação e crescimento econômico, ressalta que o impacto da educação no crescimento econômico deve estar aliado à abertura do mercado e à segurança institucional, alertando ainda que o que impulsiona a economia é a qualidade da educação e não a quantidade.

Acrescente-se que, desde a década de 1990, estudos internacionais realizados pela Comissão Econômica para a América Latina e o Caribe (Cepal) têm apontado a necessidade de no mínimo 12 anos de escolaridade para se sair da pobreza. Sem dúvida, tanto os estudos de Barbosa Filho e Pessoa (2009) quanto a posição de Hanushek e as pesquisas de organismos internacionais apresentam médias e, portanto, devem ser contextualizados nas análises de casos concretos.

No caso brasileiro, é importante salientar que diversos estudos apontam a redução das desigualdades sociais no País nos últimos anos, com a consequente diminuição da população em estado de extrema pobreza (cf. Neri, 2010). No entanto, entre os fatores associados a esse resultado estão o Plano Real, o programa Bolsa Família, o aumento do salário mínimo e das aposentadorias, ou seja, nenhum deles está relacionado diretamente à educação. Esses dados nos dão a dimensão da complexidade da relação entre educação, crescimento econômico e diminuição das desigualdades sociais.

Dado esse ponto de partida, a tese principal de Educação básica no Brasil - expressa em dois textos assinados por Fernando Veloso, um dos organizadores da publicação - enfatiza que, para se alcançar uma melhoria da qualidade da educação, é necessária a implementação de três mecanismos institucionais:

Responsabilização dos atores educacionais pelos resultados da educação por meio de um sistema de bônus para incentivar o desempenho 
dos alunos. Os exemplos citados são relativos às redes estaduais de ensino de São Paulo e de Pernambuco.

Competição entre as escolas por recursos públicos. Segundo o autor, o Fundo de Manutenção e Desenvolvimento da Educação Básica e de Valorização dos Profissionais da Educação (Fundeb), que repassa aos Estados e municípios um determinado valor por aluno, deveria se estender para mecanismos que chegassem até as escolas. Ele cita a competição por alunos como no sistema de vouchers.

Descentralização e autonomia das escolas mediante um contrato de gestão entre governo e escolas que condicione o repasse de recursos ao cumprimento de metas de desempenho. Destaca-se aqui o papel do gestor e dos pais no acompanhamento escolar dos filhos.

Ao analisar as lições aprendidas das últimas reformas educacionais, Veloso destaca que as pesquisas internacionais têm apontado a qualidade do professor como determinante fundamental no nível de aprendizado dos alunos. No entanto, o autor enfatiza que, dada a dificuldade de mensurar essa variável, ele optou por destacar a necessidade de mudanças no arranjo institucional para se alcançar melhores resultados na qualidade da educação. Essa posição assumida por Veloso acaba por não levar em conta aspectos fundamentais que não deveriam ser considerados separadamente das questões institucionais, em especial as condições para que o trabalho do professor possa ser organizado coletivamente e realizado de modo satisfatório.

Para a discussão do primeiro mecanismo apontado por Veloso, ou seja, a criação de sistemas de incentivos para se alcançar melhor desempenho, este artigo mobiliza ideias presentes em outros capítulos do livro que apontam alguns limites a essa posição.

Soares e Marotta (2009) alertam para o risco de que a criação dos sistemas de premiação por resultados possa aumentar as desigualdades escolares, uma vez que o professor pode optar por trabalhar mais com os melhores alunos para aumentar a média da turma e abandonar de vez os alunos com maiores dificuldades. Os autores citam a pesquisa de Soares e Andrade (2006), baseada em dados de escolas de Belo Horizonte, na qual se demonstra que as diferenças entre os indicadores de aprendizagem dos diferentes níveis socioeconômicos tendem a ser maiores nas escolas com melhor desempenho médio, ou seja, nesse caso a qualidade da escola e a equidade estão em uma correlação inversa. A equidade e a justiça escolar precisam passar, então, pela garantia de que alguns pontos mínimos devem ser assegurados para todos.

Por outro lado, Gremaud e Fernandes (2009), ao analisarem sistemas de avaliação, indicadores e metas, advertem para as distorções possíveis dos sistemas de incentivos, como o estreitamento do currículo e, assim como Soares e Marotta, citam a possibilidade de exclusão de alunos com baixa proficiência. Sem dúvida, a criação do Índice de Desenvolvimento da Educação Básica (Ideb) representou um avanço fundamental no sistema educacional, contudo, não pode ser absolutizado como único parâmetro da educação. Como destacam os autores acima, o Ideb não nos diz dos 
processos educacionais da sala de aula, dos professores, das escolas e dos contextos sociais e educacionais que afetam diretamente a educação e seus resultados. Em relação ao estreitamento do currículo, o Ideb se refere apenas a Matemática e a Língua Portuguesa e, quanto a esta última, somente aos aspectos relativos à leitura, sem abordar a escrita. Enfim, o alerta é que devemos aperfeiçoar o Ideb; foi o que fez o Estado de São Paulo, ao incluir um parâmetro de equidade com a criação do Índice de Desenvolvimento da Educação do Estado de São Paulo (Idesp). Posições acríticas ou eleitoreiras podem levar a palavras de ordem como: elevar o Ideb a qualquer custo para que nossos resultados educacionais sejam competitivos internacionalmente, sem de fato elevarmos a qualidade da educação para todos.

Acrescentamos ainda as teses de Ferraz (2009) que, ao estudar os sistemas de São Paulo e Pernambuco, conclui que, para esses mecanismos darem certo, é fundamental que tenham transparência e que haja credibilidade das regras. O autor ressalta que a volatilidade das políticas brasileiras coloca em risco esse sistema, que necessita de avaliações futuras para se aprofundarem os resultados obtidos.

Serão comentadas aqui as duas primeiras ponderações sobre os sistemas de bonificação por resultados. Obviamente, esse é um tema extremamente polêmico, que tem os sindicatos como ferrenhos adversários. Sem dúvida, é preciso muita cautela para implantar qualquer tipo de incentivo de premiação. É importante não esquecer que, em 2008, o sistema financeiro mundial entrou em colapso e uma de suas maiores vulnerabilidades situava-se nos bônus despropositais concedidos aos altos executivos. No caso do sistema financeiro, a busca por maiores bônus não levava em conta os altos riscos que eram assumidos e, em consequência, ameaçavam a sustentabilidade das empresas e do conjunto do sistema e terminaram por derrubá-la.

No sistema educacional brasileiro, marcado por desigualdades de partida, como apontam tanto Soares e Marotta (2009) quanto Ribeiro e Menezes Filho (2009) em Educação básica no Brasil, e em cujo âmbito os resultados, as causas e as consequências nem sempre são mensuráveis, o risco de um sistema de incentivos aumentar o hiato educacional é grande. Dado que a consolidação do desenvolvimento brasileiro passa pela maior qualificação da mão de obra e que a educação é um importante fator de diminuição das desigualdades, o risco de se deixar para trás uma parcela significativa da população poderá ter consequências graves ao País como um todo.

A necessidade de se pensar mais seriamente em resultados é fruto das inúmeras avaliações nacionais e internacionais que trouxeram à tona, de forma mais concreta, o baixo nível de nossa educação. Assim, responsabilizar os educadores pela aprendizagem dos alunos é um ponto de fundamental importância. No entanto, é também essencial levar em conta que a quase universalização do ensino fundamental gerou um novo contorno de escola, com enormes desafios, e que os professores e as secretarias de educação não têm ainda embasamento suficiente para 
lidar com essa realidade. Precisamos de estudos e de experiências que considerem, especialmente, a relação da escola com as populações de alta vulnerabilidade que estavam fora da escola ou eram excluídas precocemente pela prática da reprovação em massa. Como mostra Veloso (2009a, p. 10), é notório que o aumento da cobertura escolar e a diminuição das taxas de reprovação provocaram uma redução significativa do percentual de alunos que têm um desempenho escolar (no caso, Língua Portuguesa) adequado ao que se espera de sua série. A responsabilização dos educadores é necessária, mas não deve vir só, e sim acompanhada de uma pergunta mais ampla: nós, como sociedade, sabemos fazer escola de qualidade para as populações mais vulneráveis? A responsabilização pura e simples e os mecanismos de bonificação, por vezes, deixam a ideia de que os caminhos são conhecidos e bem acessíveis, bastando políticas gerais de distribuição de recursos e incentivos aos educadores - acompanhados de pressões sobre eles. É preciso ir além e pensar na reorganização das escolas para que possam atender aqueles que ela conseguiu matricular e aumentar a permanência.

Exemplos como o do Estado de São Paulo, em que a premiação é dada de acordo com metas que partem de patamares de cada escola e em que toda a equipe é premiada, buscaram minimizar alguns desses aspectos e devem ser acompanhados para que se possa avaliar os seus resultados. Dadas as dimensões e as diferenças dos sistemas de ensino em um país como o Brasil, há que se encontrar diferentes mecanismos que possam responsabilizar os professores e os diretores pelos resultados da aprendizagem, sem perder o eixo da equidade como vital para o desenvolvimento do País.

Alguns educadores, como Freitas (2007), também alertam para o risco de esse sistema de responsabilização e premiação criar uma escola para ricos e outra para pobres, ao mesmo tempo que acentuam um ocultamento da qualidade da educação, notadamente aquela que é oferecida às populações mais pobres. Ou seja, como já levantamos anteriormente, seguindo as análises de Soares e Marotta (2009), as escolas podem priorizar os bons alunos para aumentar a média, excluindo paulatinamente ou relegando a segundo plano aqueles com mais dificuldades. Em resumo, os mais pobres e os alunos com mais dificuldades podem perambular pelo sistema, mesmo com as médias crescendo. Freitas lembra ainda que, ao levar em conta a taxa de repetência, o Ideb pode induzir a liberação do fluxo escolar sem a preocupação com a aprendizagem. Ao criticar o sistema de avaliação baseado na responsabilização adotado pelo Ministério da Educação (MEC), o autor propõe uma ampliação do conceito de avaliação em que se levem em conta o sistema, a escola e a sala de aula, em uma articulação entre a avaliação municipal e as avaliações do Estado e da União. A avaliação institucional da escola é colocada pelo autor como o elo entre a avaliação externa de sistema e a escola e seus profissionais, com o objetivo de se criar uma reflexão coletiva na escola a fim de que ela assuma a responsabilização em conjunto com o Estado, ou seja, em um sentido bilateral de responsabilização. 
O segundo mecanismo apontado por Veloso pressupõe um sistema de competição por alunos e por recursos similar ao que já acontece entre as escolas privadas, que atuam no mercado educacional. No sistema educacional brasileiro não há modelos de vouchers ou escolas charter, como apresentado em alguns dos artigos. Além disso, é importante salientar que as avaliações sobre os dois sistemas mencionados acima apresentam resultados variáveis e as comparações com as escolas públicas não trazem conclusões definitivas. Portanto, qualquer tentativa de implantação desses sistemas no Brasil deve buscar explicitar os resultados dessas avaliações e analisar o contexto brasileiro. Não é objetivo aqui destacar as grandes diferenças culturais que nos separam dos Estados Unidos e até mesmo do Chile, países onde esses sistemas têm vigência. Basta o comentário, en passant, de que não somos uma sociedade em que os valores do individualismo competitivo sejam tão fortes quanto na norte-americana. Esse comentário foi feito para o bem ou para o mal, conforme o gosto do interlocutor, mas certamente não será uma competição artificial entre escolas que levará à melhoria da qualidade da educação.

A ideia de uma competição entre as escolas pressupõe unidades com um corpo docente estável, o que não acontece na maioria delas, e também que os pais de alunos acompanharão os resultados dos filhos de modo a procurar as melhores escolas. Sim, este último aspecto é válido para pais de camadas médias ou aqueles de camadas pobres que têm uma preocupação prioritária com a educação, sabem qual é a melhor escola do bairro e têm condições para assumir os custos e o trabalho implicados no deslocamento diário, duas vezes por dia num intervalo de tempo curto, entre o local de moradia e a escola. No entanto, isso não se aplica à maioria dessas famílias. A experiência mostra que os pais dos alunos pobres, de alta vulnerabilidade, colocarão seus filhos nas escolas mais próximas de sua casa, pois o conjunto de instabilidades que rodeia suas vidas impossibilita uma preocupação que lhes exija mais tempo para levar seus filhos a uma escola distante, a não ser quando não exista opção perto de seu local de residência. Neste último caso, em geral, o absenteísmo é grande, ocasionando perdas significativas no aprendizado dos alunos. Importante ressaltar ainda que, ao menos no caso do Estado de São Paulo, não são os pais, mas as secretarias de educação que detêm o poder final sobre as matrículas, ou seja, a secretaria pode mudar de acordo com os critérios de localização da residência. Finalmente, a opção mencionada por Veloso, de aplicar às escolas um sistema similar ao Fundeb, ou seja, de repasse de recursos pelo número de alunos, corre o risco de resultar em escolas abarrotadas de alunos, inviabilizando sua gestão.

Mas o que parece ser o obstáculo central, para não se considerar a competição como um dos mecanismos essenciais para a melhoria da qualidade da educação, é o fato de que no Brasil estamos longe de alcançar um patamar básico para todas as escolas, ainda que em um mesmo município. Como ressalta Dubet (2004), é preciso garantir um mínimo de recursos e proteção aos mais fracos e desfavorecidos de modo a limitar os efeitos dos sistemas meritocráticos que muitas vezes acabam por manter 
ou acentuar as desigualdades sociais. As escolas lidam com realidades distintas, principalmente se considerarmos aquelas localizadas nas periferias dos grandes centros, que atendem uma clientela de alta vulnerabilidade; elas, em geral, possuem um corpo docente altamente instável e não dispõem de uma infraestrutura escolar que ofereça condições mínimas de funcionamento. Também há que se considerar as enormes diferenças entre escolas rurais e urbanas. O discurso da responsabilização que deve ser feito e concretizado chega até essas escolas mais precarizadas como o de culpabilização, pois o professor não vê condições para alcançar as metas propostas e não conta com o apoio das secretarias de educação para fazê-lo. Essa situação gera impotência e maior fechamento da escola para dentro de seus muros, além de desencanto e, em alguns casos, renúncia à responsabilização e cumprimento burocrático das tarefas.

Para terminar a discussão sobre esse aspecto, é importante salientar que um sistema de incentivos, qualquer que seja ele, instala paralelamente uma competição entre as escolas, pois provavelmente (a se conferir) os professores logo estarão procurando se transferir para as escolas mais bem posicionadas nas avaliações, com o objetivo de obter maiores chances de bônus ao final do ano. Obviamente, se essa situação se comprovar como verdadeira, as escolas com maiores dificuldades ficarão relegadas cada vez mais a um corpo docente instável e com menor preparo. Esse aspecto reforça a colocação supracitada, de que corremos o risco de ver uma parcela significativa da população sem condições de acessar uma educação de qualidade, o que poderá comprometer nossos indicadores de desenvolvimento e combate à pobreza.

O terceiro mecanismo apontado por Veloso diz respeito à autonomia e à descentralização das escolas, dimensão que alcançou um consenso entre os diferentes segmentos ligados à educação. Em um país de tamanho continental, é fundamental a garantia de descentralização e autonomia das escolas que deem conta da diversidade cultural e socioeconômica dos alunos e dessas instituições. Veloso destaca a importância da capacitação técnica do diretor e do envolvimento dos pais de alunos, aspectos sem dúvida de importância fundamental no todo da escola. Temos assistido a diversas experiências em que o diretor fez toda a diferença nos resultados da escola e também conhecemos (por observação direta ou leitura) experiências em que o envolvimento de pais levou algumas escolas a reverterem um quadro de violência e drogas internamente aos seus muros. O desafio está em levar essas experiências isoladas para os sistemas de redes, sem a dependência de um personagem-herói. Assim, para além da gestão, elemento fundamental, mas não suficiente, é necessária uma reflexão sobre as dimensões pedagógicas que envolvem o professor - ator descartado por Veloso de suas análises - e o contexto sociopolítico dos municípios. Nesse sentido, precisamos avançar na profissionalização da educação, uma vez que ainda temos inúmeros municípios, especialmente os mais pobres e com mais baixo Ideb, em que a educação é moeda de troca e instrumento de favores políticos e onde os profissionais da secretaria de educação têm muito pouco preparo e conhecimento acerca de gestão e de escola. 
O MEC tem trabalhado nessa direção por meio de programas como o Plano de Ações Articuladas (PAR). Faz-se necessário um real avanço na articulação entre as esferas educacionais federal, estadual e municipal, com o objetivo de garantir a descentralização e a autonomia das escolas norteadas por critérios universais de qualidade e por preceitos pedagógicos assumidos pelo Estado e por uma supervisão sistemática por parte dos órgãos centrais.

\section{O lugar da escola e da família}

Soares e Marotta (2009) buscam modelos que reflitam qualidade e maior equidade. Eles citam o sociólogo francês Dubet (2004) para caracterizar o que seria uma escola justa: para a escola ser considerada justa (ou menos injusta), é preciso que as diferenças educacionais nela observadas não reflitam as desigualdades sociais e econômicas entre os alunos. Para o autor brasileiro, a escola pode fazer a diferença se usar melhor seus recursos físicos e humanos; ele adverte ainda que a dimensão pedagógica deve ser estudada mais cuidadosamente.

Ao adentrar para as questões internas à escola, o estudo de Ribeiro e Menezes Filho (2009) coloca como pergunta-chave: quais variáveis são as maiores responsáveis pelo desempenho dos alunos em provas como o Sistema de Avaliação de Rendimento Escolar do Estado de São Paulo (Saresp) e a Prova Brasil de âmbito federal? O autor faz uma minuciosa análise baseada em modelos estatísticos de regressão e aponta que as intervenções na escola ou na sala de aula são responsáveis por $20 \%$ do desempenho dos alunos a curto prazo. Também enfatiza, como em seus outros estudos, a importância do impacto da escolaridade dos pais e da pré-escola. Em sua conclusão, Ribeiro e Menezes Filho destacam que a variação das notas é explicada em $60 \%$ por diferenças entre alunos dentro de uma mesma sala, não capturadas pelas variáveis socioeconômicas, e 40\% explicam-se em proporção igual entre as características dos alunos, da escola e da turma. Segundo a pesquisa, as principais características do aluno que têm impacto em seu desempenho dizem respeito a: cor da pele, escolaridade dos pais e preocupação destes com o estudo e frequência à pré-escola. Quanto à escola, as características são: um corpo docente permanente com professores concursados, estável e sem muitas faltas. Também tem um papel importante a presença de um diretor com experiência e boa formação, mas, segundo o autor, não necessariamente ligada à faculdade de Educação.

Soares e Marotta preferem outra abordagem que não o método de regressão, pois, para eles, esses modelos descrevem o comportamento da média de desempenho dos alunos, configurando um cenário que não seria real. Exemplifica seu raciocínio o fato de que uma mesma média em duas regiões distintas pode expressar diferenças muito grandes na distribuição das competências individuais. Em seu estudo, eles procuram tomar como unidade de análise o aluno, mas para neutralizar as características 
individuais/idiossincráticas, consideram grupos de alunos definidos por suas características sociais e demográficas. Como técnica, usam a comparação entre as distribuições de desempenho desses grupos. Assumem, nesse modelo, que as diferenças entre as distribuições de desempenho de grupos de alunos indicam sempre desigualdades educacionais e não escolhas individuais.

Apesar de objetivos e metodologias diferentes, parte dos resultados encontrados por Soares e Marotta está em conformidade com o estudo de Ribeiro e Menezes Filho. Ao analisar os determinantes da melhoria do rendimento escolar, estes últimos destacam achados de estudos anteriores, que apontam para $70 \%$ o peso das variáveis relativas à estrutura familiar, especialmente a escolaridade dos pais, na explicação da variação das notas entre os alunos. Partindo de uma análise diferente, Soares e Marotta ressaltam que os resultados de seu estudo mostram que a herança sociocultural, as experiências sociais cristalizadas antes de o aluno ser admitido na escola e a segmentação social das escolas explicam a variação do desempenho dos alunos. Para eles, essa conclusão reforça a tese de Bourdieu sobre a escola como modelo de reprodução da escola, mas ressalta, como já mencionado, que as dimensões pedagógicas dessa instituição precisam ser mais bem compreendidas e podem fazer a diferença.

Os desafios de entender alguns dos entraves da educação básica no Brasil estão colocados no artigo de Marcelo Neri (2009) acerca da evasão escolar e as motivações daqueles que ele designa como "sem escola". A questão central que orienta seu estudo é: o que leva o adolescente a sair da escola? O autor enfatiza os resultados de pesquisas que demonstram que mais educação gera ganhos tanto em termos de eficiência econômica como de equidade distributiva. Nesse contexto, seu objetivo é elucidar a existência do paradoxo de baixo investimento em educação no País, apesar dos altos prêmios privados esperados, cujo corolário coletivo é a alta e persistente desigualdade social brasileira.

Tomando como base os resultados da Pesquisa Nacional por Amostra de Domicílios (Pnad) de 2006, o autor classifica os três principais motivos de os jovens estarem fora da escola: 1) dificuldade de acesso (10\%); 2) trabalho e geração de renda (27\%); e 3) falta intrínseca de interesse (40\%). Neri propõe, como conclusão, o estudo das causas da evasão a partir de três tipos básicos de motivação: 1) desconhecimento ou miopia dos gestores públicos, restringindo a oferta dos serviços educacionais; 2) falta de interesse dos pais e dos alunos por desconhecimento ou miopia dos retornos da educação ou pela baixa qualidade desta; e 3) restrição de renda e necessidade de trabalhar. Esses pontos serão retomados abaixo a partir de um contexto mais amplo das questões sociais.

\section{Educação no contexto da vulnerabilidade social $^{1}$}

A reflexão sobre essas colocações de Neri (2009), assim como sobre os pressupostos principais do livro Educação básica no Brasil, leva à discussão
${ }^{1}$ Vulnerabilidade social é definida em função dos vários recursos que um agente (indivíduo ou instituição) precisaria possuir para fazer frente às forças da sociedade que determinam sua vida. Para não estar em situação de vulnerabilidade social, precisaria ter condições de aproveitar as estruturas de oportunidades criadas pelo mercado, pelo Estado e pela sociedade de modo a tomar decisões voluntárias que lhe permitam satisfazer suas necessidades, desenvolver suas potencialidades e realizar seus projetos (Érnica, 2009). 
de aspectos que dizem respeito diretamente à pobreza e, em especial, às famílias moradoras dos grandes centros urbanos. No momento atual, esse tema nos leva a discutir as políticas de transferência de renda, expressas pelo Bolsa Família e por outros programas que beneficiam a frequência à escola, o que deveria reduzir os números da ausência dos jovens por falta de renda. Como os dados são de 2006, provavelmente não haviam captado os impactos de ampliação do Bolsa Família para os filhos até 17 anos. No entanto, o maior índice de motivos para a evasão diz respeito à falta intrínseca de interesse, questão muito vaga e ampla, mas que significa mais do que apenas falta de informação a respeito dos retornos da educação ou de preocupação dos pais com esta. Sem dúvida, é uma questão complexa que ultrapassa os limites deste artigo, porém serão pincelados alguns pontos importantes, já discutidos em estudo anterior (Setubal, 2009). Eles apontam para outras perspectivas não discutidas no volume Educação básica no Brasil, mas que parecem fundamentais e devem ser levadas em consideração se realmente quisermos superar os entraves educacionais brasileiros e alcançar uma educação de qualidade. Como assinala Lisboa, no prefácio do livro em discussão, é importante o confronto com a realidade para podermos superar os desafios que ela impõe.

Considerando-se apenas as populações dos grandes centros urbanos, geralmente morando nas regiões periféricas, o cenário é da marginalidade social e econômica: famílias vivem em áreas de mananciais, sem documentação dos terrenos, com energia elétrica clandestina, trabalho precário, rodeadas por drogas e pelo tráfico. Nesse cruzamento do lícito com o ilícito, jovens e adolescentes desfilam com roupas, acessórios e cortes de cabelo da moda, têm seu perfil no Orkut, seguem ídolos no Twitter, usam celulares e frequentam shopping centers das regiões mais próximas. O cenário não é linear, são pessoas que vivem o dia a dia da pobreza e da extrema pobreza, mas que dialogam com os apetrechos do mundo da tecnologia e dos bens de consumo, inclusive bens voltados à população de alta renda.

Nesse caleidoscópio da sociedade contemporânea, instala-se na escola uma violência simbólica, muitas vezes camuflada, perpassando as interações sociais ali construídas por meio de diferentes atitudes e regras invisíveis. Alguns exemplos: criação de obstáculos ao acolhimento de alunos que retornam à escola, geralmente oriundos de famílias de alta vulnerabilidade; distância entre o currículo formal e a realidade do mundo desses discentes; desvalorização da história e das vivências desses alunos e de suas famílias; culpabilização da família pelo malogro escolar dos filhos; dificuldade da escola em aceitar e lidar com a diversidade, a diferença e o preconceito. Essas atitudes, embora de difícil medição, são muitas vezes determinantes nos baixos resultados de aprendizagem e na evasão e abandono da escola. De um lado, escolas não conhecem o território do seu entorno e as condições socioculturais dos seus alunos, assumindo posições preconceituosas e desistindo do papel de garantir a aprendizagem de todos os discentes. Assiste-se à própria instituição de 
ensino atuar como legitimadora da evasão, como se abandonar a escola fosse "um bom negócio", uma vez que permitiria que o jovem trabalhasse e melhorasse a condição social da família. De outro lado, encontram-se pais que não têm modelo de referência de como apoiar os filhos na sua trajetória escolar, sentindo-se distantes e excluídos da escola de seus filhos.

Enfim, escola e comunidades vulneráveis constituem mundos regidos por ordens opostas, uma vez que a instituição de ensino é o espaço da legalidade e da burocracia, muitas vezes o único espaço público de algumas comunidades que vivem em uma tênue fronteira entre o legal e o ilegal, cercadas pela presença ameaçadora do tráfico de drogas. Cidadania implica convivência social e, se a escola é o espaço da construção da cidadania, é o espaço para a aprendizagem de normas e práticas que reflitam esse diálogo de convivência, permeado pelo reconhecimento do outro como sujeito de direitos. Uma sociedade mais justa e com equidade exige que todos os indivíduos sejam reconhecidos em sua dignidade pessoal e os diferentes grupos sociais aceitos e respeitados em suas diferenças materiais e simbólicas.

O parágrafo acima certamente soará como retórica para muitos que acreditam apenas em resultados quantitativos. No entanto, conforme destacado no início deste artigo, para alcançarmos uma educação básica de qualidade para todos, é importante a superação de preconceitos e a inclusão dos achados e estudos realizados pelos diferentes grupos compromissados com a educação. Muito já se avançou na construção de consensos em torno de metas a serem alcançadas por nossa sociedade, mas muito ainda temos pela frente. Os próximos passos são mais difíceis, pois exigem que se entre nas escolas, nos territórios, a fim de se apreender como as diferentes realidades agem cada uma de sua maneira e quais resultados alcançados apontam novos caminhos e saídas.

Nesse sentido, os pressupostos fundamentais de Educação básica no Brasil estão centrados no que Veloso denomina mecanismos institucionais e referem-se à gestão do sistema como um todo. Sem dúvida, todos esses aspectos são fundamentais e não é possível pensar a melhoria da qualidade da educação sem levar em conta a gestão da escola e das redes de ensino. A tensão dos diferentes pontos de vista parece localizar-se no conteúdo e no objetivo dessa gestão, que não se dá no vazio e não é a mesma para todas as escolas nem para todas as regiões do País. Na compreensão de muitos educadores, de forma geral, a gestão só tem sentido em função de um projeto pedagógico que organize o espaço de ensino-aprendizagem dos alunos. Assim, não é possível pensar em extremos marcados por uma gestão pautada por "burocratismos", "assistencialismos", "economicismos", "projetismos" ou qualquer outro "ismo" da moda. A gestão deve dar suporte ao projeto pedagógico da escola, um projeto que expresse de forma clara a função social dessa instituição dentro de uma concepção de autonomia e responsabilização pelo desempenho dos alunos. Responsabilização implica colocar não apenas o diretor, mas também o professor no centro das políticas educacionais 
por meio da valorização da profissão, de capacitação continuada e do suporte didático para a sala de aula. Precisamos de pesquisas que entrem nas salas de aula para analisar o fazer pedagógico nas suas diferentes dimensões, assim como o trabalho docente que não acontece de maneira isolada como querem alguns, mas de forma coletiva, ao lidar com todas as características, os problemas e a cultura instalada na escola onde o professor atua. Assim, a responsabilização tem a ver com os resultados da escola, mas também com as políticas educacionais que deem suporte aos resultados; é uma estrada de mão dupla. E, finalmente, a responsabilização e o sistema de premiação, qualquer que seja ele, têm que ter como limite e eixo central de implementação as questões de equidade e das desigualdades sociais.

\section{Equidade social como eixo para se pensar a gestão escolar}

Sozinhas e isoladas, as escolas não têm condições de uma atuação que garanta a aprendizagem de todos os seus alunos. Daí a necessidade premente de se pensar em um novo paradigma que dê conta de atender as distintas especificidades dos diferentes territórios que compõem o cenário nacional brasileiro. Partindo de aspectos levantados neste trabalho - a garantia da descentralização dos sistemas e a autonomia da escola, a explicitação de metas em contrapartida ao recebimento de recursos, a importância do papel do diretor, sua capacitação e experiência, o incentivo a um corpo docente concursado e mais estável nas escolas, a universalização da educação infantil e a ampliação da rede de creches, o envolvimento dos pais e a garantia de políticas pedagógicas norteadas pela equidade -, levantamos algumas novas dimensões. Elas talvez sejam de difícil mensuração, mas são apoiadas em estudos, na prática e no conhecimento das escolas dos grandes centros urbanos e merecem uma reflexão mais aprofundada.

Considerando-se as questões e os pontos discutidos em relação aos mecanismos institucionais de gestão, especialmente quanto aos riscos de se aumentar as desigualdades entre as escolas, são destacadas a seguir quatro dimensões apresentadas como um conjunto de ações dirigidas a todas as escolas, mas que devem ser mais firmemente implementadas e supervisionadas naquelas localizadas nas áreas de maior vulnerabilidade social.

Com a preocupação de não aumentar as desigualdades entre as escolas e deixar para trás uma parcela significativa de alunos, como analisado no decorrer deste artigo, a busca de uma qualidade de educação para todos deve levar em conta os seguintes fatores: 1) articulação entre a educação, as políticas sociais e os equipamentos públicos nos territórios; ${ }^{2}$ 2) currículos e metodologias mais adequados ao mundo contemporâneo e à realidade escolar; 3) apoio pedagógico e acompanhamento próximo dos alunos com maiores dificuldades; 4) o professor no centro da educação de qualidade. 


\section{Articulação entre a educação, as políticas sociais e os equipamentos públicos nos territórios}

Os territórios marcados por um alto índice de vulnerabilidade social acabam por se constituir em regiões segregadas e isoladas do fluxo da cidade e dos centros dos próprios bairros onde estão inseridos. Assim, escolas aí localizadas sofrem as influências limitadoras do território, que se traduzem nos mais baixos índices de desempenho escolar (Érnica, 2009). As políticas educacionais precisam ter como apoio equipamentos de saúde, cultura e esportes nas diferentes regiões dos centros urbanos. Obviamente, essa condição não está na governabilidade da educação, mas é preciso que se tenha clareza do efeito território na aprendizagem dos alunos, como têm apontado estudos mais recentes. Nesse contexto, políticas de combate à pobreza são importantes e mostram ganhos na educação, pois a alta vulnerabilidade social de parcela significativa da população brasileira exige um conjunto de políticas sociais em articulação com a educação nos territórios concretos onde se localizam as escolas. Como já mencionamos anteriormente, os dados demonstram que os dois momentos de redução dos índices de pobreza nos últimos anos não tiveram uma explicação educacional: Plano Real e políticas sociais do governo Lula (Bolsa Família, aumento de salário mínimo e aposentadorias). Eles corroboram, desse modo, nossa afirmação quanto à importância da articulação das políticas sociais com a escola.

Com relação à educação propriamente dita, referimo-nos primeiramente à importância de novos equipamentos de creches e educação infantil para atender a demanda já existente. As pesquisas e estudos nacionais e internacionais têm apontado para a importância da educação nos primeiros anos como forma de assegurar maior equidade e melhor desempenho no ensino fundamental.

Outro aspecto a ser destacado, quando se pensa no território e, especialmente, nas populações de alta vulnerabilidade social, é a possibilidade de uma educação integral que faça uso de equipamentos como clubes, centros culturais, bibliotecas e parques. Uma educação integral implica também a consideração da importância da articulação da educação com as políticas de assistência social e saúde. Nesse sentido, agentes sociais e de saúde podem prestar serviços importantes que deem maior estabilidade às famílias, liberando-as para acompanhar mais de perto seus filhos na escola. Além disso, esses agentes podem, sobretudo, ser portadores de referências, valores e normas de comportamento importantes para a permanência na escola de alunos de alta vulnerabilidade social. Políticas de esportes e cultura podem também se constituir em importantes meios de potencializar a aprendizagem e a convivência social dos alunos.

\section{Currículos e metodologias mais adequados ao mundo contemporâneo e à realidade escolar}

O mundo contemporâneo exige da escola, não só no Brasil, mas em escala mundial, uma mudança de paradigma que leve em conta que os 
meios de comunicação, a internet e as redes sociais constituem fontes de informação e conhecimento paralelas à instituição escolar. A quantidade de conhecimento a que se tem acesso por esses novos meios é incalculável e, portanto, impossível de ser transmitida pela escola. A construção do conhecimento na sociedade contemporânea não é linear e firmada apenas no texto escrito. Hoje, a construção baseada em recortes, hipertexto, fragmentos, imagens, enfim, uma diversidade imensa de possibilidades, coloca-se para cada indivíduo e pode ser sintetizada no zapear. Obtemos informação e construímos conhecimento por meio do zapear na televisão ou na internet, entre notícias, vídeos, filmes, shows, textos etc. Temos muitas informações e pouca análise. Na avalanche de notícias, as vozes ficam niveladas sem uma historização e contextualização adequadas, como se fossem da mesma importância; tudo aparece pasteurizado. Saber analisar e distinguir quais conhecimentos são válidos e significativos será a principal habilidade necessária no mundo do século 21 .

A escola é o local privilegiado da transmissão do conhecimento, mas sua lógica ainda está norteada pelo texto escrito e linearmente construído, sem levar em conta as novas concepções e linguagens acessíveis a uma parcela cada vez maior da população, inclusive entre as famílias de maior vulnerabilidade. Pesquisas apontam a existência de 80 mil lan houses no Brasil. Na direção das políticas implementadas no território, temos a possibilidade de políticas públicas serem articuladas com esses estabelecimentos com o objetivo de garantir melhores resultados de aprendizagem.

Acrescente-se a esse quadro a falta de incorporação, ao currículo, das histórias, dos valores, da arte e dos costumes das comunidades onde a escola se insere. Assim, além da falta das novas linguagens, pais e alunos não se identificam com os conteúdos transmitidos pela escola e não se reconhecem neles.

Claro, ainda temos sérias deficiências relativas à alfabetização e a conceitos básicos de Matemática, como apontam os resultados da Prova Brasil. No entanto, em que pese às disputas pelos métodos, totalmente fora de lugar, os resultados têm melhorado a cada avaliação e os caminhos estão dados por meio de várias experiências vitoriosas que têm sido registradas em diferentes regiões do País.

A distância entre a escola, os alunos e as famílias não se restringe às populações de maior vulnerabilidade, mas, sem dúvida, aí as consequências são muito mais nefastas. Não se trata obviamente de criar um currículo para ricos e outro para pobres, nem de adaptar de forma reduzida um currículo para os mais pobres, e sim de repensar nosso currículo, que é demasiado extenso se comparado com o de outros países que têm melhores patamares educacionais que o nosso. A quantidade excessiva de conteúdos faz com que os professores nunca tenham tempo de chegar até o final e, principalmente, gera uma falta de foco e desconhecimento do que é prioritário para se trabalhar. Assim, cada escola ou cada professor faz o que acha melhor, ou, na maioria das vezes, ensina aquilo que domina ou conhece com mais segurança. Estudos têm mostrado que, especialmente 
no segundo ciclo do ensino fundamental, os professores não sabem quais conteúdos devem ser trabalhados.

Repensar um currículo mais enxuto e por isso mais forte - levando em conta a nova realidade do mundo contemporâneo, com diferentes fontes de acesso ao conhecimento - exige que se enfatizem, paralelamente aos conteúdos, as habilidades de aprender a aprender, de buscar, selecionar e criticar novos conhecimentos que surgem a cada dia na sociedade, assim como as habilidades de aprender a ser e aprender a conviver. Pressupõe-se nessa concepção que, com a descentralização e a autonomia, cada rede de ensino poderá apoiar as escolas para que empreendam a adequação desses conteúdos básicos à realidade de sua comunidade escolar e do mundo contemporâneo.

\section{Apoio pedagógico e acompanhamento próximo dos alunos com maiores dificuldades}

Parece haver um consenso de que toda criança pode aprender, a diferença está no tempo e na forma de aprender de cada uma. Ao analisar as boas práticas de municípios que garantem o direito de aprender, o Fundo das Nações Unidas para a Infância (Unicef) ressalta que educar a todos implica acompanhar de perto a evolução de cada criança, partindo do ponto em que cada uma se encontra; no vaivém dos conteúdos, garante-se a aprendizagem. As metodologias são diversas: reforço, reenturmação e implementação de figuras, como o professor de apoio, o professor comunitário e o orientador educacional. As possibilidades são várias, e as políticas públicas nessa direção têm começado a ser implementadas em alguns municípios. O que importa é o lema: "Um a um, nenhum a menos".

Isso exige um conjunto de políticas que contemplem a capacitação dos professores que não são formados para compreender e atender esses alunos que se sentem completamente desamparados; uma política explícita de priorização da equidade social e a formação dos diretores nessa direção; materiais pedagógicos específicos e, portanto, recursos. Essas condições pressupõem principalmente um ambiente escolar bem organizado em função do ensino com foco na aprendizagem.

Sem dúvida, podemos encontrar inúmeros exemplos de escolas com uma estrutura de ensino-aprendizagem bem organizada e com bons resultados educacionais. No entanto, não podemos nos ater a escolas isoladas, o desafio que se coloca é como alcançar uma melhoria na qualidade de ensino nas redes do sistema de forma consistente e, sobretudo, com continuidade.

Finalmente, todo o debate educacional só faz sentido se pensarmos na sociedade como um todo, e não no individuo de forma isolada. É na escola, na vivência cotidiana, e não apenas virtual, que se descobrem diferentes modos de vida e se tem a possibilidade de viver valores coletivos que ultrapassam interesses familiares. É a possibilidade de construção 
de uma exterioridade que se abre a novos saberes, é o reconhecimento da alteridade e da construção de conhecimentos universais. A escola é também o espaço de uma sociedade democrática, muitas vezes é o primeiro espaço público com que a criança tem um contato mais próximo. É a possibilidade de sair do espaço privado, levar em conta pontos de vista do outro e construir saberes objetivos. Na escola, a criança interage com o grupo, com a classe, com a instituição, com o bairro, com a cidade, com o mundo. A utopia é construirmos uma escola aberta à comunidade, uma comunidade educadora onde todos os seus equipamentos estejam voltados para a educação e para o conhecimento e possam embasar a sociedade do século 21.

\section{O professor no centro da educação de qualidade}

Para que o desempenho escolar de nossos alunos alcance melhores resultados, são necessários professores bons, competentes, comprometidos e apoiados pedagogicamente pela direção da escola e pelos órgãos centrais. A responsabilização pelos resultados precisa ter como contrapartida as condições necessárias para o esforço nacional de alcançarmos patamares de qualidade.

As condições de formação são pouco satisfatórias e o não reconhecimento e a falta de valorização social marcam a atividade docente na sociedade brasileira atual. Paralelamente, é preciso garantir salários dignos com o objetivo de atrair bons profissionais para essa carreira. O piso nacional da categoria foi aprovado pelo Congresso Nacional em 2007, mas ainda há muito a ser conquistado na direção do cumprimento do piso e da implementação de planos de carreira.

Não é possível, no espaço deste artigo, dar conta de todos os aspectos que envolvem a temática do professor; por isso, serão enfatizadas apenas a sua centralidade nesse debate e a necessidade de pensarmos uma formação inicial e continuada de forma articulada e integrada ao currículo e às novas configurações da escola. O apoio dado pelas secretarias deve ter como contrapartida uma supervisão adequada. No caso das escolas em áreas de alta vulnerabilidade social, há que se pensar em condições específicas que deem conta das dimensões mencionadas acima.

O caminho não é simples e exige um esforço de todos, tanto dos governos como da sociedade civil e dos pais de alunos, no sentido de buscarmos uma visão de educação mais sistêmica, ajustada às necessidades do mundo moderno; uma política de educação que leve em conta as questões de gestão e, portanto, de seus mecanismos institucionais, de forma simultânea aos aspectos pedagógicos; e uma visão de educação na qual o professor e o trabalho docente ocupem lugares centrais, associada à compreensão de que o esforço nacional pela melhoria da qualidade da educação passa também pela articulação de políticas sociais de forma integrada à escola. 


\section{Referências bibliográficas}

ALMEIDA, Ana Maria F. O assalto à educação pelos economistas. Tempo Social, Revista de Sociologia da USP, São Paulo, v. 20, n. 1, 2008.

ARREGUI, Carola C. Relatório de avaliação do Programa Ação Família São Miguel Paulista. São Paulo: Fundação Tide Setubal, 2009.

BARBOSA FILHO, F. H.; PESSOA, S. A. Educação, crescimento e distribuição de renda: a experiência brasileira em perspectiva histórica. In: VELOSO, Fernando et al. (Orgs.). Educação básica no Brasil: construindo o país do futuro. Rio de Janeiro: Elsevier, 2009. p. 51-72.

COX, Cristian; SCHWARTZMAN, Simon. Políticas educacionais e coesão social: uma agenda latino-americana. São Paulo: Campus, 2009.

DUBET, François. O que é uma escola justa? Cadernos de Pesquisa, São Paulo, v. 34, n. 123, p, 539-555, set./dez. 2004.

ÉRNICA, Mauricio. Educação e vulnerabilidade social em São Miguel Paulista. São Paulo, Fundação Tide Setubal, 2009. (Textos para Discussão $\mathrm{n}^{\circ}$ 2). Disponível em: <http://www.fundacaotidesetubal.org. $\mathrm{br} / \mathrm{ftas} /$ site.php?mdl $=$ textosGop $=$ lertextoGid $=24>$.

FERRAZ, C. Sistemas educacionais baseados em desempenho, metas de qualidade e a remuneração de professores: os casos de Pernambuco e São Paulo. In: VELOSO, Fernando et al. (Orgs.). Educação básica no Brasil: construindo o país do futuro. Rio de Janeiro: Elsevier, 2009.

FISHLOW, Albert. Brazilian size distribution of income. American Economic Association: Papers and Proceedings, Nashville, p. 391-402, 1972.

FREITAS, Luiz Carlos de. Eliminação adiada: o caso das classes populares no interior da escola e a ocultação da (má) qualidade do ensino. Educação G Sociedade, Campinas, v. 28, n. 100 [n. especial], p. 965-987, out. 2007.

GREMAUD, A. P.; FERNANDES, R. Qualidade da educação: avaliação, indicadores e meta. In: VELOSO, Fernando et al. (Orgs.). Educação básica no Brasil: construindo o país do futuro. Rio de Janeiro: Elsevier, 2009. p. 213-238.

HANUSHEK, Eric. Educação é dinheiro. Veja, n. 2078, n 37, 17 set. 2008. Disponível em: <http://veja.abril.com.br/170908/entrevista.shtml>.

LANGONI, Carlos. Distribuição da renda e desenvolvimento econômico do Brasil. Rio de Janeiro: Expressão e Cultura, 1973. 
LISBOA, Marcos de Barros. Prefácio. In: VELOSO, Fernando et al. (Orgs.). Educação básica no Brasil: construindo o país do futuro. Rio de Janeiro: Elsevier, 2009.

NERI, Marcelo Cortês. O paradoxo da evasão e as motivações dos sem escola. In: VELOSO, Fernando et al. (Orgs.). Educação básica no Brasil: construindo o país do futuro. Rio de Janeiro: Elsevier, 2009. p. 25-50.

NERI, Marcelo Cortês. Cresceu e veio para ficar. O Estado de S. Paulo, São Paulo, Caderno Aliás, p. J4, 7 fev. 2010.

RIBEIRO, F. P.; MENEZES FILHO, N. A. Os determinantes da melhoria do rendimento escolar. In: VELOSO, Fernando et al. (Orgs.). Educação básica no Brasil: construindo o país do futuro. Rio de Janeiro: Elsevier, 2009. p. 171-188.

SETUBAL, Maria Alice. Os desafios de uma educação de qualidade em comunidades de alta vulnerabilidade: escola, família e comunidade. Cadernos Cenpec, São Paulo, n. 6, primeiro semestre, 2009.

SILVA, Anderson Paulino da; BRANDÃO, André; Dalt, Salete da. Educação e pobreza: o impacto das condicionalidades do programa bolsa família. Revista Contemporânea de Educação, UFRJ, Rio de Janeiro, v. 4, n. 8, p. 296-313, ago./set. 2009. Disponível em: < http:// www.educacao.ufrj.br/revista/indice/numero8/artigos/05_Educacao_e_ pobreza_o_impacto_das_condicionalidades_do_programa_bolsa_ familia.pdf $>$.

SOARES, J. F.; ANDRADE, R. Nível socioeconômico, qualidade e equidade das escolas de Belo Horizonte. Ensaio: Avaliação de Políticas Públicas em Educação, Rio de Janeiro, v. 14, n. 50, 2006.

SOARES, J. F.; MAROTTA, L. Desigualdades no sistema de ensino fundamental brasileiro. In: VELOSO, Fernando et al. (Orgs.). Educação básica no Brasil: construindo o país do futuro. Rio de Janeiro: Elsevier, 2009. p. 73-91.

VELOSO, F. 15 Anos de avanços na educação no Brasil: onde estamos? In: VELOSO, Fernando et al. (Orgs.). Educação básica no Brasil: construindo o país do futuro. Rio de Janeiro: Elsevier, 2009a. p. 3-24.

VELOSO, F. Experiências de reforma educacional nas últimas duas décadas: o que podemos aprender? In: VELOSO, Fernando et al. (Orgs.). Educação básica no Brasil: construindo o país do futuro. Rio de Janeiro: Elsevier, 2009b. p. 191-211. 
VELOSO, Fernando et al. (Orgs.). Educação básica no Brasil:

construindo o país do futuro. Rio de Janeiro: Elsevier, 2009.

Maria Alice Setubal, doutora em Psicologia da Educação pela Pontifícia Universidade Católica de São Paulo (PUC-SP), é diretora do Centro de Estudos e Pesquisas em Educação, Cultura e Ação Comunitária (Cenpec) e presidente do Conselho da Fundação Tide Setubal.

e-mail:msetubal@ftas.org.br

Recebido em 18 de setembro de 2009.

Aprovado em 19 de abril de 2010. 